\title{
Clinical Placement: Experiences, School and Hospital-based Gaps and Challenges of Undergraduate Nursing Students of the University of Cape Coast
}

\author{
Theodora Dedo $\mathrm{Azu}^{1 *} \quad$ Andrews Adjei Druye ${ }^{2 *} \quad$ Eugene Owusu-Acheampong ${ }^{3 *}$ \\ 1.Department of Maternal and Child Health Nursing, School of Nursing and Midwifery, College of Health and \\ Allied Sciences, University of Cape Coast, Ghana. \\ 2.Department of Adult Health Nursing, School of Nursing and Midwifery, College of Health and Allied Sciences, \\ University of Cape Coast, Ghana \\ 3. Department of Secretaryship and Management Studies, Cape Coast Technical University, P. O. Box DL 50, \\ Cape Coast, Ghana
}

\begin{abstract}
The goal of the study was to assess the school-based and hospital-based gaps and challenges among undergraduate nursing students. The specific objectives of the study was identify the gaps between school-based and hospital-based learning, explore students' clinical practice experiences and to determine the challenges students encounter during clinical placement. The Explanatory Mixed Method Design was used for the study. For the quantitative part, the simple random sampling technique was used to select 141 study participants. Questionnaires were used to collect numeric data. Quantitative data was analysed using IBM SPSS version 21. For the qualitative part, purposive sampling was used to select five participants for interviewing. Braun and Clarke (2006) steps for thematic analysis was employed to analyse the responses for the interviewing. The qualitative data was used to validate the quantitative results. The findings from the quantitative and qualitative aspects of the study point to common gaps and challenges and experiences of nursing students. The findings showed a consensus on differences in types of equipment and availability of equipment, learning experiences and clinical nursing practices between the hospital and school settings. Challenges with students attending more errands, poor supervision and combining school and academic work were also highlighted in the two data sets. However, the two data sets suggest that nurses create an enabling environment for the students to meet their learning objectives. This study has highlighted areas that require improvement and further research. Gaps and challenges with school learning and clinical placement in terms of making students aware of their objectives, availability of equipment, ensuring proper supervision and feedback need to be addressed.
\end{abstract}

Keywords: Undergraduate nursing, clinical placement, hospital learning, theory-practice

DOI: $10.7176 / \mathrm{JEP} / 11-5-04$

Publication date: February $29^{\text {th }} 2020$

\section{Introduction}

The clinical placement programme is a human resource development activity meant to enable students' link theory to practice. The essence is to enhance the competencies of students for better employability after graduation. Students learn to relate concepts and theory to practice to gain real work experiences (OwusuAcheampong, Azu \& Appiah-Williams, 2014). Nursing education must give students a comprehensive knowledge-base to support critical thinking and clinical decision-making (Walker \& Mann, 2016). Despite the recent development in clinical skills centers with advanced technology which allows for simulation of clinical skills, good clinical learning arenas are still crucial in learning nursing skills, clinical reasoning and developing nursing professionals for future practice (Benner, Sutphen \& Leonard, 2010; Edwards, Smith, Courtney, Finlayson \& Chapman, 2004; Myrick et al., 2006). Clinical practice education is an integral part of a nursing programme (Porter, Morphet, Missen \& Raymond, 2013).

Clinical placement for nursing students is fundamental to tertiary nursing programmes but continues to have multifaceted challenges (Ford, Courtney-Pratt, Marlow, Cooper, Williams \& Mason, 2016). Among these factors are poor supervision of students by both clinical and teaching staff due to shortage of staff, attrition of nurses, lack of collaboration between hospital and teaching staff, students outnumbering patients on the ward, unavailability of placements sites for students and increasing number of nursing students in Ghanaian universities (Atakro \& Gross, 2016; Health Workforce Australia, 2013).

Though there have been several studies (e.g Papastavrou, Dimitriadou, Tsangari \& Andreou, 2016; Porter, Morphet, Missen \& Raymond, 2013) on clinical placement, none of these studies have assessed the school-based and hospital-based gaps and challenges among undergraduate nursing students in the University of Cape Coast. It is in view of the existing literature gap that this study is very important as it seeks to fill the gap in clinical nursing practice in the University of Cape Coast. The findings of the study are intended to serve as literature for other studies that would be conducted in clinical practice. It will also inform stakeholders including teaching and 
clinical staff involved in the training of nurses especially graduate nurses and guide them in decision making on means of improving clinical placement for optimal learning experiences of nursing students.

\subsection{Review of related literature}

Papastavrou, Dimitriadou, Tsangari \& Andreou (2016) study asserted that it was paramount that students had positive learning experiences during clinical placement. In another study conducted in Ghana by Atakro \& Gross, 2019 , it was found that nursing students had the opportunity to see varieties of clinical conditions and used complex medical equipment which made their experiences positive during clinical placement. In contrast, Adjei, Sarpong, Attafuah, Amerti \& Akosah (2018) in a study to determine the experiences of students' nurses regarding intra-semester clinical placement in Ghana, found out that clinical placement was stressful, and this affected students' academic performance. Asirifi et al, (2017) commented that to ensure patient safety and build competency levels of student nurses it was paramount to facilitate effective clinical supervision and teaching to meet the needs of the students.

There is the need for institution and hospital-based partnership approach for clinical teaching to enhance readiness of nursing graduates to work after schooling (Patterson, Boyd \& Mnatzaganian, 2017). University nursing lecturers, clinical instructors and clinical preceptors need to continue to give practical teaching support to students and to clinical nursing staff involved in clinical practice teaching (Leonard, McCutcheon \& Rogers, 2016). Grealish and Smale (2011) claim that there is greater chance of nursing students having positive learning experiences during clinical placement if there is an effective collaboration between all stakeholders in nursing education.

Gaining insight into the content of assessment during clinical placement is very important for students because student learning process is highly dependent on feedback and students' ability to own their learning (Vae, Engstrom, Martensson \& Lofmark, 2018). Feedback to students are supposed to be constructive and supportive (Vae, Engström, Mårtensson, \& Löfmark, 2018). Existing literature on student nurses' experiences with clinical placement has shown both positive and negative experiences. Atakro \& Gross (2019) found that nursing students who had the opportunity to see varieties of clinical conditions and used complex medical equipment made their experiences positive during clinical placement. Some negative experiences reported during clinical placement include stress, lack of professional knowledge and skills during clinical practice, anxiety due to fear, self-doubt, poor teacher behaviour, theory-practice gap, inadequate clinical supervision, lack of clarity with professional role and emotional challenges with certain types of nursing care (Weurlander et al, 2018; Jamshidi, Molazem, Sharif, Torabizadeh, \& Najafi Kalyani, 2016). To ensure patient safety and build competency levels of student nurses, it was paramount to facilitate effective clinical supervision and teaching to meet their learning needs (Weurlander et al, 2018).

\subsection{Methods}

The research is underpinned by the pragmatist philosophy. The approach was the Explanatory Sequential Mixed Method. In this approach, quantitative data collection and analysis are conducted first followed by qualitative data collection and analysis to validate the quantitative data (Creswell \& Clark, 2017). The population of the study was all second, third and fourth-year regular nursing students of the School of Nursing and Midwifery, University of Cape Coast. The first-year students were excluded because they are basically taught general science course and only start nursing courses in their second year. For the quantitative part of the study, a simple random sampling technique was used to select participants to partake in the study. Israel (1992) was used to calculate a sample size of 141. Structured questionnaire was administered to participants in the study. Quantitative data analysis was done with the assistance of IBM SPSS version 25. Data were interpreted using descriptive statistics. Tables and charts were generated to interpret data accordingly. As regards the qualitative part, purposive sampling was used to select eight participants for a Focus Group Discussion. This was to explore the clinical placement experiences of students. Qualitative responses obtained was analysed using Braun and Clarke (2006) thematic analysis. The qualitative data was used to validate the quantitative results using the sideby-side comparison approach for similarities and differences (Creswell \& Clark, 2017). 
4.0 Results

Table 1: Demographic Characteristics

\begin{tabular}{llll}
\hline Variables & & Frequency & Percentage \\
\hline Sex & Male & 40 & 28.4 \\
& Female & 101 & 71.6 \\
Age & Below 20 & 9 & 6.4 \\
& $20-24$ & 115 & 81.6 \\
& $24-29$ & 17 & 12 \\
Level of entry into programme & Level 100 & 130 & 92.2 \\
& Level 200 & 8 & 5.7 \\
& Level 300 & 3 & 2.1 \\
Current level & Level 200 & 60 & 42.6 \\
& Level 300 & 67 & 47.5 \\
& Level 400 & 14 & 9.9 \\
Level of experience before admission & Veteran & 6 & 4.3 \\
& Generic & 135 & 95.7 \\
\hline
\end{tabular}

Source: Field Survey, 2019

Table 1 shows the demographic characteristics of the respondents in the study. The table indicates the sex, age, level of entry into the programme, current level that participants are in and level of experiences as health care professionals (veterans) before admission into the undergraduate programme. The majority of participants $101(71.6 \%)$ were females whiles males constituted $40(28.4 \%)$.

With respect to the level of entry into the nursing programme, the data revealed the majority of participants $130(92.2 \%)$ entered the baccalaureate nursing programme at level 100 and the least $3(2.1 \%)$ participants entered at level 300. Sixty participants are currently in level 200,67 and 14 participants are also in level 300 and 400 respectively.

Most of the participants 135 (95.7\%) are straight from the Senior High School (Generic) and had no experience in the health care delivery system whiles, 6 representing $4.3 \%$ have some level of health care training and experiences.

\subsection{Students Learning Experiences during Clinical Placement}

The study sought to assess students' learning experiences during clinical placement. The independent variables included students carrying out nursing activities under supervision, nurses looking for and creating learning situation for students to achieve their objectives and feedback on tasks performed under supervision was constructive and timely, clinical placement enhancing students' communication skills with staff and clients as well as students achieving their learning objectives during clinical placement. Cronbach's alpha for the 6 items on the learning experiences of students' nurses during clinical placement was .772. The value for the Cronbach's alpha was high and gives an indication of the reliability of the variables. Tables. 3 presents the results of students learning experiences based on descriptive statistics. In describing the findings, we combined strongly agree and agree as "agree" and strongly disagree and disagree as "disagree". 
Table 3: Students learning experiences during clinical placement

\begin{tabular}{|c|c|c|c|}
\hline Responses & Frequency $(\mathrm{N}=141)$ & Percentage $(100 \%)$ & Agree/disagree \\
\hline \multicolumn{4}{|c|}{ 3.1 Students carried out nursing activities under supervision } \\
\hline Strongly disagree & 9 & 6.4 & $23(16.1 \%)$ \\
\hline Disagree & 14 & 9.9 & \\
\hline Undecided & 7 & 5.0 & \\
\hline Agree & 82 & 58.2 & \\
\hline Strongly agree & 29 & 20.6 & $111(78.7 \%)$ \\
\hline \multicolumn{4}{|c|}{ 3.2 Nurses looking for and creating learning situations for students to meet their learning objectives } \\
\hline Strongly disagree & 13 & 9.2 & $48(34 \%)$ \\
\hline Disagree & 35 & 24.8 & \\
\hline Uncertain & 14 & 9.9 & \\
\hline Agree & 64 & 45.4 & \\
\hline Strongly agree & 15 & 10.6 & $79(56 \%)$ \\
\hline \multicolumn{4}{|c|}{ 3.3 Feeling confident when performing nursing activities } \\
\hline Strongly disagree & 2 & 1.4 & $7(4.9 \%)$ \\
\hline Disagree & 5 & 3.5 & \\
\hline Uncertain & 17 & 12.1 & \\
\hline Agree & 88 & 62.4 & \\
\hline Strongly agree & 29 & 20.6 & $117(83.0 \%)$ \\
\hline \multicolumn{4}{|c|}{ 3.4 Communication skills with staff and clients at clinical placement were enhanced } \\
\hline Strongly disagree & 3 & 2.1 & $10(9.2 \%)$ \\
\hline Disagree & 10 & 7.1 & \\
\hline Uncertain & 17 & 12. & \\
\hline Agree & 78 & 55.3 & \\
\hline Strongly agree & 33 & 24.4 & $111(79.7 \%)$ \\
\hline \multicolumn{4}{|c|}{ 3.5 Students achieving their objectives during clinical placement } \\
\hline Strongly disagree & 16 & 11.3 & $48(34 \%)$ \\
\hline Disagree & 32 & 22.7 & \\
\hline Uncertain & 32 & 22.7 & \\
\hline Agree & 61 & 43.3 & \\
\hline Strongly agree & 11 & 7.8 & $72(51.1 \%)$ \\
\hline \multicolumn{4}{|c|}{ 3.6 Feedback on nursing activities performed under supervision was constructive and timely } \\
\hline Strongly disagree & 5 & 3.5 & $31(21.9 \%)$ \\
\hline Disagree & 26 & 18.4 & \\
\hline Uncertain & 26 & 18.4 & \\
\hline Agree & 69 & 48.9 & \\
\hline Strongly agree & 15 & 10.6 & $76(59.5 \%)$ \\
\hline
\end{tabular}

Source: Fieldwork, 2019

Table 3 shows a summary of the students learning experience during clinical placement. The students were asked to respond to a Likert scale questionnaire on whether they strongly agreed, agreed, were undecided, disagreed or strongly disagreed with the variable.

\subsection{Students carried out nursing activities under supervision}

The data showed that the majority, 111(78.7\%) of the respondents agreed with carrying out nursing activities under supervision. A few 23(16.1\%) disagreed and 7(5\%) were undecided. The findings contrast with that of the FGD. Almost all the FGD participants commented about poor supervision by the nursing staff. According to them, the nurses are too busy to supervise them and did not care about them because they were university students. For example, participant 1 shared this: "some of the clinical staff don't mind us...., they say that we are degree nursing students they prefer the "green" (diploma), nursing students".

Participant 2: also said this: "Clinical placement is interesting however; we are at times not supervised by anyone".

4.3 Nurses looking for and creating learning situations for students to meet their learning objectives With respect to nurses looking for and creating learning situations within the clinical placement sites to meet the learning objective needs of the students, Table 3 revealed that slightly more than half $79(56 \%)$ of the respondents agreed that nurses created the opportunities for learning within the clinical setting. However, 
approximately a third 48(34\%) disagreed.

The results of the FGD shows a similar trend to the quantitative results. There was a missed reaction regarding whether the nurses create an enabling environment for them to meet their objectives. For example, participant 2 said this "the experiences we get depends on the nurse on duty you meet during clinical. Some of them are very friendly and tell us what to do, others don't say anything to us". (P2)

Similarly, participants 3 and 4 commented as follows:

"Only one nurse on my ward calls us to discuss what we have learnt when she was free". (P3)

"Some nurses teach us whenever they are free... most of the time they are busy though" (P4)

The results, therefore, show that despite the duties nurses had towards clinical care of their patients; some created avenues and opportunities for students to learn and meet their objectives for the placement whiles others do not.

\subsection{Feeling confident when performing nursing activities}

On the issue of students feeling confident when performing clinical nursing activities on their clients under supervision, the majority of $117(83.0 \%)$ of the respondents agreed and only $7(4.9 \%)$ disagreed.

\subsection{Feedback on nursing activities performed under supervision was constructive and timely}

Table 3 revealed that the majority $117(83.0 \%$ ) of the respondents agreed whereas a small number of respondents $7(4.9 \%)$ disagreed. The results, therefore indicate that most students will prefer performing nursing activities under supervision with constructive and timely feedback to enhance their clinical learning.

Majority $111(79.7 \%$ ) of participants indicated that their communications skills with staff and clients at the clinical placement sites were enhanced however, a few 10(9.2\%) disagreed. This result shows that students' communication skills that is vital to nursing care of client and for nurse to nurse interaction is enhanced during clinical placement. Effective communication is to be embraced to harness the positive benefits on patient care and student clinical learning.

As regards to students achieving their objectives during clinical placement, it was found that collectively more than half $80(56.7 \%)$ of participants either were undecided $32(22.7 \%)$, disagreed $32(22.7 \%)$ and strongly disagreed $16(11.3 \%)$ with meeting their objectives at the clinical placement site. However, collectively 61 participants representing $43.3 \%$ both agreed $50(35.5 \%)$ and strongly agreed $11(7.8 \%)$ with meeting all their objectives during their clinical placement. This result shows that majority may not have achieved their clinical objectives, and this is a source of worry for clinical teaching and learning.

Gaps in School-Based and Hospital Based Learning Table 4: Means of Gaps in School-Based and Hospital-Based Learning

\begin{tabular}{lcc}
\hline Gaps in School-Based and Hospital-Based Learning & Mean & Std. Deviation \\
\hline $\begin{array}{l}\text { Students awareness of objectives before clinical placement } \\
\text { Similarity of nursing activities carried at clinical skills laboratory } \\
\text { and nursing unit }\end{array}$ & 2.6950 & 1.18403 \\
$\begin{array}{l}\text { Facilities and equipment at the hospital are adequate for clinical } \\
\text { Learning }\end{array}$ & 2.4539 & 1.24179 \\
$\begin{array}{l}\text { The clinical instructors and lecturers in the university visit } \\
\text { students at the hospital to address their challenges }\end{array}$ & 2.7943 & 1.28439 \\
$\begin{array}{l}\text { The clinical environment is conducive for learning } \\
\text { Students access to clinical preceptors who are present at the } \\
\text { hospital and are willing to address learning needs }\end{array}$ & 3.2411 & 1.13955 \\
\end{tabular}

Scale: 1-strongly disagree, 2-disagree, 3-uncertain, 4-agree and 5 strongly agree Source: Field Survey, 2019

Table 4 shows the results from the descriptive statistics indicate that students' awareness of objectives before attending clinical placement with a mean of 3.6879 was the strongest gap of school-based and hospitalbased learning, followed by the clinical environment being conducive for learning with a mean of 3.2411, then students access to clinical preceptors present at the clinical sites willing to address their learning had a mean of 3.0284. This was followed by clinical instructors and lecturers visiting students at the hospital to address challenges, similarity of nursing activities carried out at clinical skills laboratory and nursing unit then finally facilities and equipment at the hospital are adequate for clinical learning. The findings indicate that the most important gap for students regarding clinical learning were students having access to the learning objectives before going for clinical placement and they considered the adequacy of facilities and equipment at the hospital for clinical learning as the least important. 
In the FGD, the students generally described similar differences in what they learn in school and the skills lab. They mentioned that there were differences in the types of equipment, and nursing care procedures they use in the skills lab and those in the hospitals. Also a number of equipment they use to practice at the skills lab are not available in the hospital and nurses have to improvise.

In connection with equipment, participant 1 said this: "Hmm, different, very different. We have some of the equipment at the skills lab but the hospitals lack some of this equipment".

Others commented on differences in nursing care procedures and learning outcome.

"the skills lab teaching is the one that we are supposed to do but at the hospital because of the workload on the nurses and inadequate ... things..., the nurses cut corners and don't do exactly what they are supposed to do. $(P 2)$

"Hmm Hmm the difference is clear. There is a clear difference between what learn at the clinical lab and at clinicals. Some of the students say that the one we learn at the clinical lab is for exams and the one we learn at clinicals is for future practice". (P4)

"What we learn at the skills lab on campus is quite different from what we see on the ward. The procedures are very different $(P 3)$

Some participants also shared their views in relation to lack of clarity of learning objectives:

"Hmm Hmm the difference is clear. There is a clear difference between what learn at the clinical lab and at clinicals. Some of the students say that the one we learn at the clinical lab is for exams and the one we learn at clinicals is for future practice”. (P5)

\section{Challenges Associated with Clinical Placement}

Table 7: Means of challenges associated with clinical placement

\begin{tabular}{lcc}
\hline Challenges associated with clinical placement & Mean & Standard deviation \\
\hline The clinical staff do not readily engage with us & 3.2411 & 1.21244 \\
There is too much work to be done & 3.0496 & 1.21494 \\
There is so much work-related stress & 3.7589 & 1.03441 \\
I do not know how I am assessed during clinical placement & 3.8369 & 1.12519 \\
I did not learn anything new & 2.2837 & 1.27238 \\
I am constantly sent on errands not related to nursing care & 3.0638 & 1.33209
\end{tabular}

Scale: 1-strongly disagree, 2-disagree, 3-uncertain, 4-agree and 5 strongly agree

Source: Field Survey, 2019

Results from table 7 indicate that the most challenging factor for students during clinical placement was that they did not know how they were assessed during clinical placement with a mean of 3.8368. To address this challenge, students are to be told how assessment for clinical placement will be done even before commencement. The next factor was that there was so much work-related stress with a mean of 3.7589. The least challenging factor for student was not learning anything new during clinical placement with a mean of 2.2837.

In the FGD, the students expressed similar challenges with clinical placement. The challenges come as a result of being engaged in errands, lack of supervision, and stress resulting from combing school work and clinical work.

A participant share this in relation to errands. It's a lot of hard work and I am sent on too many errands that are not related to nursing practice. "Hmm this clinical experience is good, I have learnt a lot but.... the staff send us on many errands". (P3)

Two participants also expressed their sentiments in relation to poor supervision:

Clinical placement is interesting however, we are at times not supervised by anyone. (P1)

Clinicals are interesting however, at times we are not supervised by anyone. We are left on our own. (P2)

Another participant also said this in relation to combining school work and clinical placements:

"We are loaded with so much work at school that clinical placement is not always enjoyable... I will be happy if we have different time for only clinical placement and different time for lectures. I mean separating the two, not putting them together". (P4)

This implies that students had the privilege of learning new things when they went for clinical placement. In the qualitative part of the study, participant 5 said; "Hmm this clinical experience is good, I have learnt a lot but.... the staff send us on many errands".

\section{Summary}

It is obvious that the findings from the quantitative and qualitative aspects of the study point to common gaps and challenges and experiences of nursing students. The findings show a consensus on differences in types of equipment and availability of equipment, learning experiences and clinical nursing practices between the clinical and school settings. Challenges with students attending more errands, poor supervision and combining school and academic work were also highlighted in the two data sets. Also, the two findings suggest that nurses create 
enabling environment for the students to meet their learning objectives.

A major disparity between the qualitative and quantitative findings concerns the results of the students learning experiences. The quantitative results show that most students agreed or strongly agreed to have a positive experience, yet the qualitative results pointed to a negative experience from the students. For example, on the question of students working under supervision $78.7 \%$ indicated yet in the FGD all the students commented about poor supervision. The findings indicated that more research is required to better understand learning experiences during clinical placements.

\section{Conclusions}

This study has highlighted areas that require improvement and further research. Gaps and challenges with school learning and clinical placement in terms making students aware of their objectives, availability of equipment, ensuring proper supervision and feedback needs to be addressed.

\section{Recommendations}

Based on the findings and conclusions, it was recommended that the faculty ensures the following:

\section{Nursing education}

1. Before students start clinical placement, objectives for the activities should be made available to them.

2. Students could be shown how they will be assessed during clinical placement to facilitate active participation in learning.

\section{Nursing practice}

1. Clinical nurses should be encouraged to create conducive environment, carry out supervision during clinical nursing activities and create more opportunities for teaching and learning for students during clinical placement.

2. Nurse educators should visit students frequently to address the challenges they face during clinical placement.

\section{Nursing research}

1. The findings indicated that more research is required to better understand the students learning experiences. Especially, a qualitative study that engages more participants using the variables in the questionnaire used for the current study and issues raised in the qualitative dimension is required.

\section{References}

Adjei, C. A., Sarpong, C., Attafuah, P. A., Amertil, N. P., \& Akosah, Y. A. (2018). "We'll check vital signs only till we finish the school": experiences of student nurses regarding intra-semester clinical placement in Ghana. BMC nursing, 17(1), 23.

Asirifi, M., Ogilvie, L., Barton, S., Aniteye, P., Stobart, K., Bilash, O., \& Kwashie, A. (2017). Assessing challenges of clinical education in a baccalaureate nursing program in Ghana. Journal of Nursing Education and Practice, 7(10), 109.

Atakro, C. A., \& Gross, J. (2016). Preceptorship versus clinical teaching partnership: literature review and recommendations for implementation in Ghana. Advances in Nursing, 2016.

Benner, P. Sutphen, M. \& Leonard, V. L. (2010) Day Educating Nurses. A Call for Radical Transformation John Wiley \& Sons, Inc, Hoboken, New Jersey.

Edwards, H., Smith, S., Courtney, M., Finlayson, K. \& Chapman, H. (2004). The impact of clinical placement location on nursing students' competence and preparedness for practice. Nurse Education Today 24, 248255.

Eick, S. A., Williamson, G. R. \& Heath, V. (2012). A systematic review of placement-related attrition in nurse education. International Journal of Nursing Studies, 49(10):1299-309.

Ford, K., Courtney-Pratt, H., Marlow, A., Cooper, J., Williams, D., \& Mason, R. (2016). Quality clinical placements: The perspectives of undergraduate nursing students and their supervising nurses. Nurse Education Today, 37, 97-102.

Grealish, L., \& Anne Smale, L. (2011). Theory before practice: Implicit assumptions about clinical nursing education in Australia as revealed through a shared critical reflection. Contemporary Nurse, 39 (1), 51-64.

Health Workforce Australia (2013). Australia's Health Workforce Services-nurses in focus Adelaide, Health Workforce Australia (2013). Retrieved from https://www1.health.gov.au

Jamshidi, N., Molazem, Z., Sharif, F., Torabizadeh, C., \& Najafi Kalyani, M. (2016). The challenges of nursing students in the clinical learning environment: A qualitative study. The Scientific World Journa, 2016.

Leonard, L., McCutcheon, K., \& Rogers, K. M. (2016). In touch to teach: Do nurse educators need to maintain 
or possess recent clinical practice to facilitate student learning? Nurse education in practice, 16(1), 148-151.

Myrick F, Phelan A, Barlow C, Sawa R, Rogers G, Hurlock D (2006) Conflict in the preceptorship or field experience: A rippling tide of silence. International Journal of Nursing Education Scholarship http://www.bepress.com/ijnes/vol3

Owusu-Acheampong E, Azu, T. D \& Asamoah-Appiah, W (2014). Industrial attachment: perspectives, conceptions and misconceptions of students at Cape Coast Polytechnic.

Papastavrou, E.,Dimitriadou, M., Tsangari, H., \& Andreou, C. (2016). Nursing students' satisfaction of the clinical learning environment: a research study. BMC nursing, 15(1), 44.

Patterson, E. E, Boyd, L., \& Mnatzaganian, G. (2017). The impact of undergraduate clinical teaching models on the perceptions of work-readiness among new graduate nurses: A cross sectional study. Nurse Education Today, 55, 101-106

Porter, J., Morphet, J., Missen, K., \& Raymond, A. (2013). Preparation for high-acuity clinical placement: confidence levels of final-year nursing students. Advances in medical education and practice, 4, 83.

University of Saskatchewan School of Nursing, (2014). Clinical placement. Retrieved from http://www.usask.ca/nursing/clinical/

Walker, M. \& Mann, R. A (2016). Exploration of mindfulness in relation to compassion, empathy and reflection within nursing education. Nurse Education. Today, 40 (2016), pp. 188-190, 10.1016/j.nedt.2016.03.005.

Weurlander, M., Lönn, A., Seeberger, A., Broberger, E., Hult, H., \& Wernerson, A. (2018). How do medical and nursing students experience emotional challenges during clinical placements? International Journal of Medical Education, 9, 74.

Vae, K. J. U., Engström, M., Mårtensson, G., \& Löfmark, A. (2018). Nursing students' and preceptors' experience of assessment during clinical practice: A multilevel repeated-interview study of studentpreceptor dyads. Nurse education in practice, 30, 13-19. 